\title{
Index of Research Access: an estimate of travel accessibility for research
}

\author{
This article was published in the following Dove Press journal: \\ Nursing: Research and Reviews \\ 24 October 2012 \\ Number of times this article has been viewed
}

\author{
Patrick McNees ${ }^{1,3}$ \\ Karen Meneses ${ }^{2}$ \\ 'School of Health Professions, ${ }^{2}$ School \\ of Nursing, University of Alabama at \\ Birmingham, ${ }^{3}$ Kirchner Private Capital \\ Group, Birmingham, Alabama, USA
}

\begin{abstract}
There is a paucity of methods that examine the relative difficulty or ease of access to research. The Index of Research Access was designed to provide a quantitative index allowing a determination of the probable ease or difficulty in accessing research participation for either an individual compared to a reference group, or for a group of individuals compared to another group or reference group. The aims of this paper are to (1) describe the major factors considered in the development of the Index of Research Access, an index of research accessibility; (2) provide the rationale and formula for the Index of Research Access; (3) describe the testing and application of the Index of Research Access using a sample of 239 women participating in a longitudinal trial of psychoeducational support interventions for breast cancer survivors; and (4) consider implications of the Index of Research Access for other research endeavors.
\end{abstract}

Keywords: methodology, distance barrier, travel barrier, research barrier

\section{Introduction}

Distance, public transportation options, social and familial support, and geographic variations are representative of factors that can limit or ease physical access to care. Yet, there is a paucity of methods that examine the relative difficulty or ease of access to research. For example, research access barriers can result in a sample that may either be inadequately described, or result in study groups that may be unbalanced. Similarly, differential results across multiple studies may be due to the differences in access to study participation. Such cross-study differentials would result if, for example, participants who do versus do not overcome access barriers that may have characteristics that can potentially influence the results. One such barrier may be travel. Travel barriers such as time, distance, and limited access to transportation to access health care may also discourage participation in research. However, there are few methods for quantifying the ease or difficulty in travel to participate in a research study.

The aims of this paper are to (1) describe the major factors considered in the development of the Index of Research Access, an index of research accessibility; (2) provide the rationale and formula for the Index of Research Access; (3) describe the testing and application of the Index of Research Access using a sample of 239 women participating in a longitudinal trial of psychoeducational support interventions for breast cancer survivors; and (4) consider implications of the Index of Research Access for other research endeavors. More generally, this paper describes the first step towards better understanding the specific effects of travel challenges: the development of a methodology for estimating and quantifying the extent of the travel challenge for each study participant.
Correspondence: Patrick McNees School of Health Professions, I705 University Blvd, School of Health Professions Building \#33I, University of Alabama at Birmingham, Birmingham, AL 32946, USA

Tel +I 2059340475

Fax +| $205975567 \mid$

Email mcneesp@uab.edu 


\section{Background}

Little is known about the effects of travel challenges on research participation. However, more has been written about access to treatment with a particular emphasis on people dwelling in rural areas. There are a plethora of barriers to access health care services as well as participation in research trials. More has been written about barriers to accessing care than has been written about barriers to participating in research. Even when considering access to care, the ease or difficulty that people face when traveling from their residence to a place where care is available has been widely discussed but not as widely researched. ${ }^{1-11} \mathrm{~A}$ few reported studies document travel barriers in accessing health care. For example, Curtis et al sought to identify and quantify nontreatment costs associated with dental treatment among patients in Australia and whether the perceived impact of costs may limit access to dental care. ${ }^{3}$ They found that patients living in remote areas had higher indirect costs for dental care. Travel costs and its impact on the family restricted access to dental services, particularly among those living in New South Wales. One might assume that similar challenges might also affect participation in research trials and possibly influence study results.

In the United States, attention has been drawn to the disparity in access for people living in rural areas. It is estimated that 60 million Americans are largely underserved by public transportation. ${ }^{12}$ That estimate suggests that roughly two out of three rural American residents have no access to public transportation. ${ }^{12}$ Such lack of access to public transportation may limit access to care among rural residents. In a Veterans Health Administration study of veterans' use of Veterans Affairs hospitals for medical-surgical care, Mooney et al found that both greater travel distance and lower population density were associated with reduced facility utilization. ${ }^{5}$ In particular, veterans from rural areas traveled farther for medical care compared with veterans living in high population density areas. While it has not been documented, one might assume that similar circumstances might influence participation in research.

In another study, Buzza et al examined the degree to which distance was a barrier to accessing health care services among rural veterans. ${ }^{2}$ Using a mixed methods approach, they examined access to primary care services at eight Veterans Health Administration clinics in the Midwestern United States. Findings indicated specific barrier examples including long travel for common diagnostic or routine care, and emergency services. Patient factors that complicated travel barriers were their health and functional status, travel costs, and work and family obligations.
Zgibor et al found an association between driving distance and glycemic control in rural areas among 3369 individuals with type II diabetes. ${ }^{11}$ They examined the driving distances to the diabetes management center of participants having good glycemic control $\left(\mathrm{A}_{1 \mathrm{c}} \leq 7 \%\right)$ compared with driving distances among those with poor glycemic control $\left(\mathrm{A}_{1 \mathrm{c}}>7.0 \%\right)$. The mean distance of travel was 13.3 miles. Findings showed that participants who drove more than 10 miles to the center were significantly more likely to have poor $\mathrm{A}_{1 \mathrm{c}}$ values.

Sarnquist et al identified poor access to human immunodeficiency virus care among rural women in California. ${ }^{8}$ They conducted interviews with 64 human immunodeficiency virus-positive rural residents and found that lack of transportation, lack of navigation within the health system, and travel more than 90 minutes to access care were the major hindrances to accessing health care.

Guidry et al likewise found that transportation for cancer care was problematic. ${ }^{4}$ The investigators compared distance and mode of transportation as a barrier among a multicultural and multiethnic population with mixed cancer diagnoses. Of the 910 surveys mailed, 593 were returned. Study results showed that some patients did not receive needed cancer treatment because of transportation access barriers. Findings showed that minority Black and Hispanic patients had an undue burden because of lack of automobile and support resources.

While the previous studies found that barriers to accessing treatment existed and were particularly problematic for rural patients, there were no published reports available that described or explored the barriers faced by potential participants in a clinical trial or research. Thus, a method for quantifying travel barriers facing potential study participants could be useful in understanding differential patterns of research study enrollment and retention as well as influence on outcome.

The Index of Research Access was designed to provide a quantitative index allowing a determination of the probable ease or difficulty in accessing research participation for either an individual compared to a reference group, or for a group of individuals compared to another group or reference group. Thus, the index is relative and not absolute. Publicly available data in the United States, free or commonly available software, and website resources were used to calculate the Index of Research Access scores. With the lack of simple and definable measures of research access, the Index of Research Access is a first step in determining a quantitative description of an individual or group of individuals' relative ease or difficulty in access to research participation. 


\section{Factors in the development of the Index of Research Access}

In an effort to identify the factors that might offer a meaningful quantitative reflection of travel to participation, consultation with experts in rural health, breast cancer survivorship, cancer treatment, engineering, and computer science was sought. These experts later served as the Index Advisory Team. Perhaps the most obvious measure of travel is distance between two sites. While distance may serve as a meaningful indicator in environments wherein there are few geographic or other barriers, a more meaningful measure for the population of participants who lived in the state of Florida was an estimate of typical travel time. A wide range of geographic and traffic factors can make the travel time vastly different for two individuals living exactly the same distance from a research site.

While the investigators considered using estimates of travel time as a single factor to estimate the magnitude of the travel barrier, such an assumption would be premised on an additional assumption: that individuals had access to a vehicle and were capable of driving themselves. It was argued that people in less densely populated areas were less likely to have access to public transportation or other alternative means of transportation from their home to a research study site. Thus, while there are many possible reasons that may impede treatment access, the investigators focused on two major factors: (1) travel ease between one's residence and the study site and (2) population density in the area immediately surrounding one's residence.

\section{Travel factor}

"Travel" was identified as a factor rather than "distance" to the nearest study site. Distance is typically conceptualized as the number of miles (or kilometers) between one's residence and some other point (eg, research site, emergency room, specialty clinic). The use of distance is appropriate in situations where considerable distances with little congestion are considered. In the United States, many western states such as Montana and Wyoming are examples of such longdistance, low-density situations. Australia presents an even more dramatic example because a great percentage of the population lives along the coast and there are vast, sparsely populated areas with little or no public transportation.

However, in a large American state such as Florida, variable congestion and other factors suggest that two people living exactly the same distance from a research facility may experience very different normal driving times between their home and the research site. Thus, rather than using absolute miles, a travel factor was calculated.

In general, the travel factor is defined as the miles between a participant's residence and the research site with adjustment for variances in typical driving time versus the time that would be expected if one could drive at a constant 50 miles per hour. The adjusted time factor is calculated in several steps which are articulated in Table 1. The operational procedure to estimate distance using MapQuest ${ }^{\circledR}$ (AOL Inc, New York, NY) is listed in Table 2.

\section{Population density}

In the United States, population density patterns vary widely from state to state and from locale to locale within states. For example, population density in the state of Florida varies from one locale to the next within a given county and even within a given zip code within the same county. For the present calculations, census track was used as the unit for analysis. In general, census track data are more discrete than zip code data. Census track data is available from public records obtained from the United States Census Bureau. The data can be downloaded in a delimited text format and subsequently imported in programs such as $\operatorname{Excel}^{\circledR}$ (Microsoft Corporation, Redmond, WA) or SPSS ${ }^{\circledR}$ (IBM Corporation, Armonk, NY).

Two data items are needed to calculate population density for a census track: (1) the population of the census track and (2) the size (ie, area represented in square miles) of the census track. Density can then be calculated by dividing population by size to determine the number of persons per square mile. However, to convert density to a measure that has some relationship to the definition of rural versus urban, an adjusted density was calculated. This calculation is performed by dividing the population per square mile by 100 since 100 persons

Table I Procedure for calculating adjusted time factor

\begin{tabular}{ll}
\hline Step I & $\begin{array}{l}\text { Divide the miles between the patient's home and the research facility by } 50 \mathrm{mph} \text {. This will result in an expected driving time if one could } \\
\text { drive at a constant } 50 \mathrm{mph} .\end{array}$ \\
Step 2 & Determine the estimated actual driving time. \\
Step 3 & Divide the expected driving time by the estimated actual driving time. \\
Outcome & Result is a figure representing adjusted time factor.
\end{tabular}

Abbreviation: mph, miles per hour. 
Table 2 Operational procedure

\begin{tabular}{ll}
\hline Step I & Use MapQuest (http://www.mapquest.com/directions/main.adp) to determine the distance and estimated driving time between the \\
research facility and the patient's home. & Use the research facility's address as the starting address. \\
Step 2 & Use the patient's street address and zip code as the destination address. (It is not necessary to enter city and state if you enter the zip code). \\
Step 3 & $\begin{array}{l}\text { Press the "Get Directions" button. MapQuest will generate directions. At the end of the directions, the approximate driving time and } \\
\text { Step } 4\end{array}$ \\
Result & Enter both driving time and distance on the spreadsheet. If time is in minutes, divide by 60.
\end{tabular}

per square mile or fewer is a commonly accepted definition of rural in the United States. The resulting adjusted density factor can be viewed in terms of how many times greater the density is than "rural" or, if under 1.0, the relative density or sparseness of the population compared to what is considered rural. It is important to note that the emphasis on "rural" in this calculation does not mean that the study must be focused on rural dwelling participants. Rather, it is simply a frequently used metric to define rural versus urban. The Index of Research Access goes beyond the binary description of rural versus urban in that it provides a relative quantitative index.

\section{Formula for the Index of Research Access}

The Index of Research Access was calculated by dividing an adjusted travel factor by an adjusted population density factor. Three formulae for the Index of Research Access shown in Table 3 include: (1) conceptual, (2) intermediate, and the (3) actual calculation formula.

\section{Evaluating the Index of Research Access}

Interest in a quantitative measure or index of research access grew out of the authors' experience with the Breast Cancer Education Intervention (BCEI), a longitudinal clinical trial that evaluated the effects of a psychoeducational intervention on quality of life for breast cancer survivors. The specific details of that study have been reported elsewhere and are briefly described as follows. ${ }^{13}$ Early-stage (0-II) breast cancer survivors within 2 years of diagnosis and 1 month after completion of primary treatment were recruited from a large regional cancer center and private oncology offices in the state of Florida. Institutional review boards at the participating institutions which complied with the Health Insurance Portability and Accountability Act Guidelines in the United States approved the study.
After completing baseline measures, 261 BCEI participants were randomly assigned to either the experimental or waitlist control group. The experimental intervention arm $(n=129)$ received three weekly face-to-face education and support survivorship sessions delivered by an intervention nurse. The sessions focused on differential aspects of quality of life including: (1) physical (fatigue, pain, menopausal symptoms, and change in body image); (2) psychological adjustment, social and family relationships, work and financial concerns; and (3) spirituality and meaning in illness. Participants received a 168-page education binder of written information and three audiotapes of instruction to supplement learning. They were contacted for monthly follow-up telephone calls or in-person visits for the subsequent 5 months. Participants assigned to the waitlist control group $(\mathrm{n}=132)$ received baseline and monthly telephone calls and visits. At 6 months of study participation, they received the education and support intervention as described above. Total participation time in the BCEI was 6 months.

The major reasons for declining participation in the BCEI included: (1) travel and distance barriers; (2) rural residence; (3) perceived lack of time; and (4) English was not the primary language. Interestingly, travel was a consideration for some who declined participation even though study inclusion criteria called for participants to live within 50 miles of the study/treatment site. This latter fact focused attention on the need to have a simple and useful way to quantify and describe travel characteristics of potential research participants.

Of the 256 participant addresses that were checked, 239 had sufficiently detailed information to allow identification of the relevant census track and determination of the estimated driving distance and time. The results of testing the Index of Research Access from the 239 participants are summarized in Table 4.

Table 3 Formulae for the Index of Research Access

\begin{tabular}{lll}
\hline Conceptual formula & Intermediate formula & Calculation formula \\
\hline IRA $=\mathrm{tf} / \mathrm{ad}$ & $\mathrm{IRA}=([\mathrm{d} \times$ adjusted $\mathrm{tf} /($ population per square mile// 00] $)$ & $\operatorname{IRA}=(\mathrm{d} \times([\mathrm{m} / 60) /(\mathrm{d} / 50]) /[\mathrm{p} / \mathrm{a} / \mathrm{I00}])$ \\
\hline
\end{tabular}

Abbreviations: a, area in square miles; ad, adjusted density; d, distance in miles; IRA, Index of Research Access; m, minutes to drive; $\mathrm{p}$, census tract population; tf, travel factor. 
Most participants lived in rather densely populated areas with a mean of 2407.5 persons per square mile (standard deviation $=1838.98)$. However, some lived in areas with as few as 4.99 residents per square mile (range $=4.99-8724.83$ ). Slightly over $30 \%$ of the participants lived in census tracks with a population density under 1000 persons per square mile and about $2 \%$ lived in areas with fewer than 100 residents per square mile. The median population density per resident was 2205.26 persons per square mile and the first, second, and third quartiles were $877.74,2205.26$, and 3783.84 , respectively.

About $35 \%$ of the participants lived within 10 miles of the treatment facility (range $=0.54-78.05$ miles). About $8 \%$ lived over 50 miles from the facility. The mean distance was 18.05 miles (standard deviation $=15.42$ ) and the median was 13.29 miles with the first, second, and third quartiles falling at $8.00,13.29$, and 23.12 miles, respectively. The estimated time to travel to and from the treatment facility varied similarly to distance but, due to differential driving conditions, was even more variable. The effects of this variability can be seen by viewing the travel factor data in Table 4 . As can be seen, the factor varied from $1.50-74.17$ with a mean of 21.19 (standard deviation $=13.91)$ and a median of 16.67 with the first, second, and third quartiles falling at 12.50, 16.67, and 28.17 , respectively.

After the Index of Research Access score was calculated, the resulting mean for the 239 participants was 8.88 (standard deviation $=53.13)$. The median was 0.94 (minimum $=0.03$, maximum $=751.50$ ). It should be noted that the participant with the maximum score lived in a census track with a population density of fewer than five people per square mile. The participant also had a travel factor that was about 35 times greater than that of the participant who lived closest to the facility. Index of Research Access first, second, and third quartiles fell at $0.35,0.94$, and 3.46 , respectively.

The distribution of Index of Research Access scores is illustrated in Figure 1. Over 50\% of the participants had Index of Research Access scores $<1.0$, indicating that many study participants lived close to the facility. Over one-third of the participants had Index of Research Access scores between 1.0 and 9.99. About $10 \%$ of the participants had Index of Research Access scores between 10 and 99.99, and 2\% had scores $\geq 100$.

\section{Discussion}

The results reflect major variations in travel challenges in this sample of 239 breast cancer survivors with the maximum Index of Research Access score being 9332 times greater than the minimum score. The third quartile Index of Research Access score is almost ten times greater than the first quartile score. To confirm the reasonableness of the Index of Research Access calculations, one might consider the profile of selected raw unadjusted data.

The greatest driving distance is over 144 times that of the least driving distance, and estimated driving times vary as much as a factor of 156 . Population density varied by a factor of almost 1750, ie, the population of the most densely populated census track was about 1750 times greater than the most sparsely populated track. To illustrate the magnitude of difference in population density, assume all of Florida had the same population density as the least densely populated census track area in the study. In such a case, in 2004 the population of the state would have been about 271,717 rather than almost 17 million. Assuming there are fewer cancer treatment and support services offered in less densely populated areas, such differences in magnitude imply huge differences in local availability of services.

\section{Limitations}

The major limitation of this work is that it is descriptive. That is, the intent was to develop and illustrate a methodology that would allow the quantification of a population characteristic that is rarely described yet may have profound influence on study participation, retention, outcomes, and intervention refinement.

Table 4 Index of Research Access scores of 239 participants

\begin{tabular}{|c|c|c|c|c|c|c|c|c|}
\hline & Mean & SD & Median & Min & Max & QI & Q2 & Q3 \\
\hline Density (persons/square mile) & 2407.50 & 1838.98 & 2205.26 & 4.99 & 8724.83 & 877.74 & 2205.26 & 3783.84 \\
\hline Distance (miles) & 18.05 & 15.42 & 13.29 & 0.54 & 78.05 & 8.00 & 13.29 & 23.12 \\
\hline Hours & 0.42 & 0.28 & 0.33 & 0.03 & 1.48 & 0.25 & 0.33 & 0.56 \\
\hline Expected time & 0.36 & 0.31 & 0.27 & 0.01 & 1.56 & 0.16 & 0.27 & 0.46 \\
\hline Adjusted time factor & 1.42 & 0.44 & 1.27 & 0.88 & 3.68 & 1.12 & 1.27 & $1.6 \mid$ \\
\hline Travel factor & 21.19 & $13.9 \mid$ & 16.67 & 1.50 & 74.17 & 12.50 & 16.67 & 28.17 \\
\hline Adjusted density & 24.08 & 18.39 & 22.05 & 0.05 & 87.25 & 8.78 & 22.05 & 37.84 \\
\hline Index of Research Access score & 8.88 & 53.13 & 0.94 & 0.03 & 751.50 & 0.35 & 0.94 & 3.46 \\
\hline
\end{tabular}

Abbreviations: Max, maximum; Min, minimum; QI, first quartile; Q2, second quartile; Q3, third quartile; SD, standard deviation. 


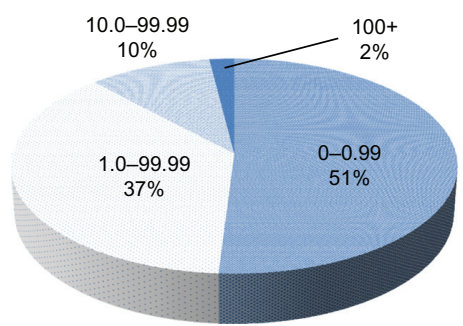

Figure I Percent of 239 study participants with Research Access Index scores in four ranges.

Note: Percent of participants with RAl scores within various ranges.

Thus, such issues as predictive validity are beyond the scope of the present work. While the Index of Research Access would not be expected to influence retention rates, the index may be important in better understanding the reasons for differential retention patterns. However, this latter assumption requires additional research.

The use of "black box" technologies like MapQuest for calculating distance and estimating driving time rely on algorithms and calculation methods that are not under the control of the investigators. It is possible that there are errors in such calculations. Some might question why MapQuest was used for estimating driving time rather than, say, Google Maps (Google Inc, Mountain View, CA). The answer lies in the reality that at the time the Index of Research Access was being developed, MapQuest held a commanding lead in market share among commercial travel enterprises. However, any reliable system can be used.

It is possible that other factors may need to be considered. For example, estimated travel cost might prove to be an important factor. It is also possible that the results from accumulation of additional data may suggest that factor weights may need to be modified. Collectively, these and other limitations suggest a number of questions for future research.

A more qualitative approach to involving potential participants may result in a richer understanding of the influence of travel barriers. While travel time was considered in present calculations, the cost associated with participation was not considered.

However, the aforementioned limitations do not detract from the fact that the Index of Research Access allowed for a beginning quantitative description of the challenges faced in accessing research participation for breast cancer survivors. The Index of Research Access also allowed a better estimate of the extent to which the two study groups were balanced in terms of travel access to study participation. Whether travel challenges go beyond issues of access and retention and actually contribute to or detract from intervention effectiveness remains a topic of future research.

\section{Conclusion}

In summary, this paper describes one methodology for estimating travel difficulty and allowing travel to be included among the participant characteristics considered when considering research study design, methods, and results.

\section{Acknowledgment}

This research was supported by the National Institute of Nursing Research and the Office of Cancer Survivorship at the National Cancer Institute (5R01-NR05332-04).

\section{Disclosure}

The authors report no conflicts of interest in this work.

\section{References}

1. Probst JC, Laditka SB, Wang JY, Johnson AO. Effects of residence and race on burden of travel for care: cross sectional analysis of the 2001 US National Household Travel Survey. BMC Health Serv Res. 2007; $7: 40$.

2. Buzza C, Ono SS, Turvey C, et al. Distance is relative: unpacking a principal barrier in rural healthcare. J Gen Intern Med. 2011;26(Suppl 2): 648-654.

3. Curtis B, Evans RW, Sbaraini A, Schwarz E. Geographic location and indirect costs as a barrier to dental treatment: a patient perspective. Aust Dent J. 2007;52(4):271-275.

4. Guidry JJ, Aday LA, Zhang D, Winn RJ. Transportation as a barrier to cancer treatment. Cancer Pract. 1997;5(6):361-366.

5. Mooney C, Zwanziger J, Phibbs CS, Schmitt S. Is travel distance a barrier to veterans' use of VA hospitals for medical surgical care? Soc Sci Med. 2000;50(12):1743-1755.

6. Neale J, Tompkins C, Sheard L. Barriers to accessing generic health and social care services: a qualitative study of injecting drug users. Health Soc Care Community. 2008;16(2):147-154.

7. Peipins LA, Graham S, Young R, et al. Time and distance barriers to mammography facilities in the Atlanta metropolitan area. J Community Health. 2011;36(4):675-683.

8. Sarnquist CC, Soni S, Hwang H, Topol BB, Mutima S, Maldonado YA. Rural HIV-infected women's access to medical care: ongoing needs in California. AIDS Care. 2011;23(7):792-796.

9. Stitzenberg KB, Sigurdson ER, Egleston BL, Starkey RB, Meropol NJ. Centralization of cancer surgery: implications for patient access to optimal care. J Clin Oncol. 2009;27(28):4671-4678.

10. Wang F, Luo W. Assessing spatial and nonspatial factors for healthcare access: towards an integrated approach to defining health professional shortage areas. Health Place. 2005;11(2):131-146.

11. Zgibor JC, Gieraltowski LB, Talbott EO, Fabio A, Sharma RK, Hassan K. The association between driving distance and glycemic control in rural areas. J Diabetes Sci Technol. 2011;5(3):494-500.

12. American Public Transportation Association. Public transportation benefits: facts. 2011. Available from: http://www.apta.com/mediacenter/ ptbenefits/Pages/FactSheet.aspx. Accessed June 27, 2012.

13. Meneses KD, McNees P, Loerzel VW, Su X, Zhang Y, Hassey LA. Transition from treatment to survivorship: effects of a psychoeducational intervention on quality of life in breast cancer survivors. Oncol Nurs Forum. 2007;34(5):1007-1016. 
Nursing: Research and Reviews

\section{Publish your work in this journal}

Nursing: Research and Reviews is an international, peer-reviewed, open access journal publishing original research, reports, reviews and commentaries on all aspects of nursing and patient care. These include patient education and counselling, ethics, management and organizational issues, diagnostics and prescribing, economics and

\section{Dovepress}

resource management, health outcomes, and improving patient safety in all settings. The manuscript management system is completely online and includes a very quick and fair peer-review system. Visit http://www.dovepress.com/testimonials.php to read real quotes from published authors.

Submit your manuscript here: http://www.dovepress.com/nursing-research-and-reviews-journal 